\title{
Comparison of biomass and lipid production under ambient carbon dioxide vigorous aeration and $3 \%$ carbon dioxide condition among the lead candidate Chlorella strains screened by various photobioreactor scales
}

\author{
Naoko Kobayashi ${ }^{1}$, Austin Barnes ${ }^{1}$, Travis Jensen ${ }^{1}$, \\ Eric Noel ${ }^{2}$, Gunjan Andlay ${ }^{4}$, Julian N. Rosenberg ${ }^{3}$, \\ Michael J. Betenbaugh ${ }^{3}$, Michael T. Guarnieri ${ }^{5}$, George A. Oyler ${ }^{1,3,4, *}$
}

${ }^{1}$ Department of Biochemistry, University of Nebraska-Lincoln 1901 Vine Street Lincoln NE 68588

${ }^{2}$ School of Biological Science, University of Nebraska-Lincoln 1104 T Street Lincoln NE 68588

${ }^{3}$ Department of Chemical \& Biomolecular Engineering, John Hopkins University 3400 North Charles Street, Baltimore, MD 21218

${ }^{4}$ Synaptic Research, 1448 South Rolling Road, Baltimore, MD 21227

${ }^{5}$ National Bioenergy Center, National Renewable Energy Laboratory, Golden, CO

*is the corresponding author 
Key words:

2 Chlorella, Chlorella sorokiniana, Chlorella vulgaris, rDNA-based phylogenetic tree, Biomass,

16 


\section{Abstract}

20 Chlorella species from the UTEX collection, classified by rDNA-based phylogenetic analysis, 21 were screened based on biomass and lipid production in different scales and modes of culture.

22 The lead candidate strains of C. sorokiniana UTEX 1230 and C. vulgaris UTEX 395 and 259

23 were compared between conditions of vigorous aeration with filtered atmospheric air and $3 \%$

$24 \mathrm{CO}_{2}$ shake-flask cultivation. The biomass of UTEX 1230 produced 2 times higher at $652 \mathrm{mg} \mathrm{L}^{-1}$

25 dry weight under both ambient $\mathrm{CO}_{2}$ vigorous aeration and $3 \% \mathrm{CO}_{2}$ conditions, while UTEX 395

26 and 259 under $3 \% \mathrm{CO}_{2}$ increased to 3 times higher at $863 \mathrm{mg} \mathrm{L}^{-1}$ dry weight than ambient $\mathrm{CO}_{2}$

27 vigorous aeration. The triacylglycerol contents of UTEX 395 and 259 increased more than 30

28 times to $30 \%$ dry weight with $3 \% \mathrm{CO}_{2}$, indicating that additional $\mathrm{CO}_{2}$ is essential for both 29 biomass and lipid accumulation in UTEX 395 and 259. 
Some microalgal species can produce biomass that is useful as a biofuel feedstock. The

unicellular green microalgae of the Chlorella genus are potential candidates for biofuel (e.g.,

33 biodiesel) production due to inherently high rates of biomass production and oil accumulation

34 with minimal nutrient requirements (Bumbak et al., 2011). Most conventional fuels, including

35 petroleum and diesel, contain aliphatic hydrocarbons that are chemically similar to the fatty acid

36 components of triacylglycerol (TAG) (Hu et al., 2008). TAGs are neutral lipids consisting of a

37 glycerol backbone esterified to three fatty acids. The fatty acid composition of Chlorella TAGs

38 is similar to that observed in higher plants, with predominantly 16- and 18-carbon fatty acids

39 (Durrett et al., 2008; Hu et al., 2008). Biodiesel refers to fatty acid components derived from

40 trans-esterification of TAGs from renewable sources, such as soybean oil or animal fats. Algal

41 oil is an attractive alternative to vegetable oils as a feedstock for biofuel production because its

42 cultivation can be maintained on land that is unsuitable for conventional agriculture while

43 yielding much higher amounts of oil per acre compared to conventional oilseed crops such as

44 soybean (Dismukes et al., 2008; Greenwell et al., 2009). Chlorella cultivation will also be

45 readily performed in industrial processes (Rodolfi et al., 2009; Schenk, 2008).

Chlorella produces substantial biomass under minimum nutrients while requiring

47 nitrogen, phosphorus and other micronutrients in the presence of light and carbon dioxide $\left(\mathrm{CO}_{2}\right)$.

48 Nutrient uptake from different manure-based anaerobic digested products and industrial effluents

49 has been evaluated for production of biomass, lipids, carbohydrates and proteins in Chlorella

50 species (Kobayashi et al., 2013; Singh et al., 2011). Production of biomass and lipid has been

51 studied broadly under different media in the Chlorella species: Chlorella vulgaris, C.

52 protothecoides, C. sorokiniana, C. zofingiensis, C. pyrenoidosa, C. minutissima and other 
53 species. For example, the biomass and lipid contents in C. vulgaris UTEX 259 were reported as

$54250 \mathrm{mg} \mathrm{L}^{-1}$ and $38 \%$ dry weight (DW), respectively, in modified Bold's Basal Medium (BBM)

55 (Liang et al., 2009) and the biomass and productivity of C. protothecoides UTEX 255 were 11.7

$56 \mathrm{~g} \mathrm{~L}^{-1}$ and $654 \mathrm{mg} \mathrm{L}^{-1}$ day $^{-1}$, respectively, under the $2.4 \mathrm{~g} \mathrm{~L}^{-1} \mathrm{KNO}_{3}$ medium (Shen et al., 2010)

57 which contains ten times higher nitrogen concentration than BBM. The biomass and lipid

58 contents in C. sorokiniana were between $165-261 \times 10^{6}$ cells ml ${ }^{-1}\left(0.82 \mathrm{~g} \mathrm{~L}^{-1}\right)$ and $13 \% \mathrm{DW}$

59 respectively (Zheng et al., 2012) and those in C. zofingiensis (ATCC 30412) were $1.9 \mathrm{~g} \mathrm{~L}^{-1}$ and

$6015 \%$ DW, respectively, in Kuhl medium (Liu et al., 2011). In C. pyrenoidosa SJTU the contents

61 of biomass and lipid were $1.6 \mathrm{~g} \mathrm{~L}^{-1}$ and $24 \%$ respectively in BG11 medium with $10 \% \mathrm{CO}_{2}$

62 (Tang et al., 2011) and in C. minutissima UTEX 2219 they were at $21-140 \times 10^{6}$ cells ml $^{-1}(61$ -

$63726 \mathrm{mg} \mathrm{L}^{-1}$ ) and 4-4.8 \% DW, respectively, in Bold $3 \mathrm{~N}$ medium (Tang et al., 2012). Although

64 much information regarding biomass and lipid production in different Chlorella species has been

65 collected, comparative analyses are limited by lack of uniformity in growth conditions.

Many Chlorella strains have previously been compared by the rDNA-based phylogenetic

67 analysis (Blanc et al., 2010; Rosenberg et al., 2013). In this study, fourteen Chlorella strains

68 from C. vulgaris, C. sorokiniana, C. kessleri, C. protothecides and C. zofingiensis species were

69 selected by ribosomal DNA (rDNA)-based phylogeny comparing the distance with $C$. variabilis

70 NC64A before biomass and lipid comparisons were pursued using a standard photoautotrophic

71 growth medium (BBM). Considering the potential biofuel applications using genetically

72 engineered Chlorella strains in the future, the candidate Chlorella strains have been compared by

73 rDNA-based phylogenetic analysis (Rosenberg et al., 2013) to C. variabilis NC64A, whose

74 genome has been elucidated (Blanc et al., 2010). In cases for related cultivars comparison of the 
75 rDNA segment including internal transcribed spacers (ITS) regions among species and

76 phylogenetic analysis are appropriate for understanding evolutionary proximity.

The production of biomass and lipids by these strains in BBM were compared using

78 different types and volumes of photobioreactors (sterilized 1 or 3 L bioreactors, $80 \mathrm{~L}$ aquarium

79 tanks and $80 \mathrm{~L}$ hanging-bags). BBM is a minimal nutrient media, which is appropriate to

80 maintain the large-scale cultures like aquarium tanks and hanging-bags. In preliminary studies at

81 the National Renewable Energy Laboratory (NREL), C. vulgaris UTEX 395 was found to have

82 more biomass production than $C$. sorokiniana UTEX 1230 in $\mathrm{BBM}$ with $2 \% \mathrm{CO}_{2}$ in $250 \mathrm{ml}$

83 shake flask at $150 \mathrm{rpm}$ and $1 \mathrm{~L}$ Roux bottle at $500 \mathrm{rpm}$ under illumination at $200 \mu \mathrm{mol} \mathrm{m}^{-2} \mathrm{~s}^{-1}$

84 (unpublished data). Interestingly, UTEX 1230 at the University of Nebraska-Lincoln (UNL) has

85 produced more biomass than UTEX 395 in BBM (pH 7.0) with vigorous aeration at a flow rate

86 of $30 \mathrm{~L} \mathrm{~min}^{-1}(0.38 \mathrm{vvm})$ containing atmospheric $\mathrm{CO}_{2}(0.04 \%)$ under fluorescence illumination

87 at $200 \mu \mathrm{mol} \mathrm{m}^{-2} \mathrm{~s}^{-1}$. Furthermore, the transcriptome of $C$. vulgaris has been analyzed in nitrogen-

88 replete and deplete conditions and high production of biomass and fatty acid methyl ester

89 (FAME) lipid contents were reported at $8 \times 10^{8}$ cells $\mathrm{ml}^{-1}$ and $10 \% \mathrm{DW}$, respectively, under the

90 nitrogen-replete while at $5 \times 10^{8}$ cells $\mathrm{ml}^{-1}$ and $60 \% \mathrm{DW}$ under the nitrogen-deplete condition

91 (Guarnieri et al., 2011). In an analogous study, the differential biomass production and lipid

92 profiles of $C$. sorokiniana UTEX 1230 have been characterized during photoautotrophy and

93 heterotrophy, yielding from 40 to $115 \times 10^{6}$ cells $\mathrm{ml}^{-1}$ and from 12 to $24 \%$ DW of FAME TAG

94 (Rosenberg et al., 2013). To compare the growth and lipid production between these and other $C$.

95 sorokiniana and C. vulgaris strains, the rDNA sequences of each strain obtained from NREL and

96 UNL were confirmed to be identical and the biomass and lipid production of the lead Chlorella

97 candidates UTEX 1230, 395 and 259 were compared under the ambient $\mathrm{CO}_{2}$ vigorous aeration 
98 and $3 \% \mathrm{CO}_{2}$ conditions at the same corresponding conditions at $25 \pm 2{ }^{\circ} \mathrm{C}$ under the light

99 intensity $200 \mu \mathrm{mol} \mathrm{m} \mathrm{s}^{-2}$ on the shaker at $150 \mathrm{rpm}$ in BBM (pH 7.0). After screening based on

100 biomass production and lipid content and composition, the most promising Chlorella strains and 101 optimal carbon sources for biofuel application are discussed.

\section{Materials and Methods}

\subsection{Algae strains and growth conditions} vacuolata, C. minutissima and $C$. zofingiensis strains were obtained from the Culture Collection of Algae at the University of Texas at Austin. C. variabilis NC64A and C. sorokiniana CS-01 109 were provided by Dr. James Van Etten at the University of Nebraska-Lincoln and Dr. Minxi 110 Wan at Johns Hopkins University, respectively. All algae strains at UNL were transferred to 111 Bold's Basal Media (BBM) (Bold, 1949) sterile agar plates containing $100 \mu \mathrm{g} \mathrm{ml}^{-1}$ tetracycline 112 and $10 \mu \mathrm{g} \mathrm{ml}^{-1}$ ampicillin and grown at $25{ }^{\circ} \mathrm{C}$ under continuous illumination at $160 \mu \mathrm{mol} \mathrm{m}^{-2} \mathrm{~s}^{-1}$. 113 The algae at NREL were maintained in BBM sterile agar plates containing $100 \mu \mathrm{g} \mathrm{ml}^{-1}$ 114 ampicillin. Liquid culture was initiated by inoculation of a single isolated colony into $5 \mathrm{ml}$ of 115 sterile BBM. The $5 \mathrm{ml}$ cultures were shaken at $250 \mathrm{rpm}$ for 7 days under continuous illumination $116\left(160 \mu \mathrm{mol} \mathrm{m}^{-2} \mathrm{~s}^{-1}\right)$ at $25^{\circ} \mathrm{C}$. 
120 solution, as described previously (Rosenberg et al., 2013; Wan et al., 2011). After boiling at 100

$121{ }^{\circ} \mathrm{C}$ for $15 \mathrm{~min}$, samples were centrifuged at $16,000 \times g$ for $2 \mathrm{~min}$ and DNA recovery was 122 quantified using a NanoDrop 2000 spectrophotometer (Thermo Fisher Scientific, Delaware, 123 USA). The primer pair designed for this study (5'-ACTCCGCCGGCACCTTATGAG-3'; 124 forward, 5'-CCGGTTCGCTCGCCGTTACTA-3'; reverse) was used to amplify the ITS region 125 with the Top Taq Master Mix Kit (Qiagen, California, USA) according to the manufacturer's 126 protocol employing thermocycler conditions with an initial melting at $95{ }^{\circ} \mathrm{C}$ for 2 min, followed 127 by 35 cycles of $\left[94^{\circ} \mathrm{C}\right.$ for $30 \mathrm{sec}, 60^{\circ} \mathrm{C}$ for $30 \mathrm{sec}, 72^{\circ} \mathrm{C}$ for $2 \mathrm{~min}$ ]; and a final elongation at 72 $128{ }^{\circ} \mathrm{C}$ for $10 \mathrm{~min}$. Amplified fragments were separated by electrophoresis on a acrylamide (1\% w:v) 129 tris-borate-EDTA gel. Confirmation of molecular weights was determined with a GeneRuler 1 130 kb Plus DNA Ladder (Fermentas, Delaware, USA) and ultimately purified using the GenCatch ${ }^{\text {TM }}$ 131 PCR Extraction Kit (Epoch).

The ITS region nucleotide sequences (Eurofins MWG Operon, Ebersberg, Germany) 133 were assembled manually and poor quality ends were removed. Sequences were saved in 134 multifasta format, and aligned using Multiple Alignment and Fast Fourier Transform (MAFFT) 135 v7.029b. The alignment was annotated to include a partial 18S, ITS1, 5.8S, and ITS2. The 136 final alignment contains $1226 \mathrm{bp}$ to $1720 \mathrm{bp}$, while some species contain a $400 \mathrm{bp}$ intron in the 137 18S (C. saccharophila SAG 211/1d and C. minutissima UTEX 2219). The phylogenic tree was 138 generated using Phylogeny by PhyML, a software package using maximum likelihood to 139 generate the tree. 1000 bootstrap replicates were used in the construction of the tree. 
All cultures at stationary phase were inoculated at $4 \times 10^{6}$ cells ml $^{-1}$ and cells growth was 143 measured by hemocytometer. Algae growth was monitored during the algal growth cycle and the 144 algae were collected at the stationary phase (Table 1) by centrifugation at 5,000 $\times g$ for $5 \mathrm{~min}$. 145 The pellet was stored at $-80{ }^{\circ} \mathrm{C}$ and lyophilized overnight and used for lipid analyses.

For the preparation of bioreactors, $15 \mathrm{ml}$ cultures were grown for 14 days and then 147 transferred to $300 \mathrm{ml} \mathrm{BBM}$ in the aerated photo-bioreactors. Chlorella liquid cultures in $250 \mathrm{ml}$, $148500 \mathrm{ml}, 1 \mathrm{~L}$ and $3 \mathrm{~L}$ were grown in photobioreactors under continuous fluorescence illumination 149 at $200 \mu \mathrm{mol} \mathrm{m}-2 \mathrm{~s}^{-1}$ in a greenhouse environment at $25 \pm 2{ }^{\circ} \mathrm{C}$. Exponential-phase cells were 150 transferred after 5 days to $3 \mathrm{~L} \mathrm{BBM}$ in the $3 \mathrm{~L}$ aerated photobioreactors and grown to the 151 stationary phase. Aeration flow for the $300 \mathrm{ml}$ and $3 \mathrm{~L}$ photo-bioreactors were maintained by an 152 air-pump (Whitewater, MTL66) with a flow rate of $30 \mathrm{~L} \mathrm{~min}^{-1}$ (0.38 vvm) (in addition to 153 agitation by spinning turbine impellers ( $180 \mathrm{rpm})$. For the aquarium tanks, the $3 \mathrm{~L}$ cultures were 154 again scaled-up and transferred to $80 \mathrm{~L} \mathrm{BBM}$ in the $170 \mathrm{~L}$ open aquarium tanks with two Power 155 Head water pumps (1500 L h${ }^{-1}$; PETCO King 225) arranged in hanging bag preparation, the $3 \mathrm{~L}$ 156 cultures were transferred to $80 \mathrm{~L} \mathrm{BBM}$ in the polyethylene hanging bag. Air stones with tubing 157 were inserted in adjacent columns providing vigorous and ascending aeration supplied from an 158 external compressed air source ( $\left.30 \mathrm{~L} \mathrm{~min}^{-1}, 0.38 \mathrm{vvm}\right)$. Both aquarium tanks and hanging bags 159 were grown in a greenhouse environment at $25 \pm 2{ }^{\circ} \mathrm{C}$. The contamination of culture was 160 monitored and checked by both microscope and the rDNA sequences. 

under the ambient $\mathrm{CO}_{2}$ vigorous aeration and $3 \% \mathrm{CO}_{2}$ conditions bioreactors for the air treatment and $150 \mathrm{ml} \mathrm{BBM}$ in the $250 \mathrm{ml}$ flasks under the $\mathrm{CO}_{2}$ condition. 166 Aeration flow was maintained by an air-pump (Whitewater, MTL66) with a flow rate of $30 \mathrm{~L}$

$167 \min ^{-1}(0.38 \mathrm{vvm})$ in addition to agitation by spinning turbine impellers $(120 \mathrm{rpm}) .3 \% \mathrm{CO}_{2}$ was 168 saturated at $23{ }^{\circ} \mathrm{C}$ in the $\mathrm{CO}_{2}$ chamber (Forma Environmental Chamber, Thermo Electron 169 Corporation, USA) and the cultures were maintained on the shaker at $150 \mathrm{rpm}$. The growth was 170 monitored during the algal growth cycle and the algae were collected at the stationary phase 171 (day-12) by centrifugation at 5,000 $\times \mathrm{g}$ for $5 \mathrm{~min}$. The pellet was stored at $-80{ }^{\circ} \mathrm{C}$ and lyophilized 172 overnight and used for lipid analyses.

\subsection{Lipid extraction}

Lipid extraction followed the procedure provided by (Kobayashi et al., 2013). The dried

176 algae pellets (100 mg) were homogenized using a mortar and a pestle with liquid nitrogen. Lipid 177 extraction was performed by a modification of the method described by (Bligh, 1959). Two ml 178 of chloroform:methanol $(1: 2, \mathrm{v}: \mathrm{v})$ containing $0.01 \%$ butyl hydroxyl toluene was added to the 179 ground cells and pooled in a glass tube. This step was repeated 3 times. $500 \mu \mathrm{g}$ of 180 tripentadecanoin (15:0 TAG, Nu-Check Prep, MN, USA) was added as an internal standard. Two $181 \mathrm{ml}$ of zirconia beads (0.7 mm, BioSpec Products, OK, USA) were added and the mixture was 182 shaken by a vortex at room temperature for $30 \mathrm{~min}$. Two $\mathrm{ml}$ of chloroform and $4 \mathrm{ml}$ of water 183 were added and vortexed. After centrifugation at 1,500 $\times g$ for $5 \mathrm{~min}$, the chloroform phase was 
184 collected and the aqueous phase was re-extracted with $5 \mathrm{ml}$ of chloroform. This step was

185 repeated 5 times. The pooled chloroform was evaporated to dryness under a stream of nitrogen.

186 Three biological replicates of total lipid content were determined gravimetrically.

\subsection{Chromatographic methods}

Thin layer chromatography (TLC) for neutral lipid separation and trans-methylation to

190 FAME were performed as previously described (Kobayashi et al., 2013). FAMEs were analyzed

191 using an Agilent 6890 Series gas-chromatography (GC) System with Agilent 5973 Network

192 Mass Selective Detector (Agilent Technologies, Delaware USA) and chromatography was 193 carried out using a $200 \mathrm{~m} \times 250 \mu \mathrm{m} \times 0.25 \mu \mathrm{m}$ Varian GC Capillary column (Varian Inc., CA, 194 USA). GC inlet was held at $270{ }^{\circ} \mathrm{C}$ and $1 \mu \mathrm{L}$ of the sample was injected with splitless or $20: 1$ 195 split. The oven temperature was programmed from $130{ }^{\circ} \mathrm{C}(10 \mathrm{~min}$ hold $)$ to $160{ }^{\circ} \mathrm{C}$ ( 7 min hold $)$, 196 from $160{ }^{\circ} \mathrm{C}$ to $190{ }^{\circ} \mathrm{C}(7 \mathrm{~min}$ hold $)$, from $190{ }^{\circ} \mathrm{C}$ to $220{ }^{\circ} \mathrm{C}\left(22 \mathrm{~min}\right.$ hold) and from $220{ }^{\circ} \mathrm{C}$ to $197250{ }^{\circ} \mathrm{C}(17 \mathrm{~min}$ hold $)$ at a rate of $10^{\circ} \mathrm{C} \mathrm{min}^{-1}$ for each step with helium as the carrier gas. The 198 total analysis time was $75 \mathrm{~min}$. The GC/MS was carried out using $70 \mathrm{eV}$ EI and the data was 199 evaluated with total ion count (TIC). The total lipid content was calculated based on the 15:0 200 TAG internal standard and the ration of peak area in total FAME composition sum and 15:0 201 FAME was applied to obtain the lipid content percentages in dry weight.

\section{Results and discussion}


The Chlorella strains used in this study were collected mainly from UTEX collection 207 (http://web.biosci.utexas.edu/utex/) and maintained in BBM, which is a minimal nutrient 208 medium for photoautotrophic algal cultivation. In order to determine the phylogenetic 209 relationships between Chlorella strains, DNA was extracted from the selected Chlorella strains 210 and analyzed by ribosomal DNA (rDNA)-based phylogenetic analysis (Fig.1). Coding regions of 211 rDNA are highly conserved among species but ITS regions are variable due to insertions, 212 deletions, and point mutations. In cases for sibling species, comparison of the rDNA segment 213 including ITS regions is appropriate for phylogenetic analysis (Ahmad et al., 2013; Cha et al., 214 2011). In comparing the genomic DNA-based Chlorella identities, the three strains were 215 identified newly by rDNA based-phylogenetic analysis with alignment by the MAFFT platform, 216 which is able to focus on only Chlorella strains, not including other genera, and supports the tree 217 with bootstrap values from 1000 replicates (Katoh, 2014). The ITS sequences of all strains listed 218 in the phylogenetic tree is released into the GenBank sequence database (Rosenberg et al., 2013). 219 While our previous rDNA-based phylogenetic analysis of Chlorella and Scenedesmus strains 220 employed the MUSLE alignment algorithm (Rosenberg et al., 2013), this study focused on 221 UTEX Chlorella strains (e.g., C. vulgaris, C. sorokiniana, C. kessleri, C. protothecoides, C. 222 fusca var vacuolata, C. minutissima and C. zofingiensis) based on MAFFT alignments (Fig. 1). 223 The relation of the closer distance with $C$. variabilis NC64A by rDNA-based phylogenetic 224 analysis with MAFFT was the same order as the previous study with MUSLE (Rosenberg et al., 225 2013), which was from C. sorokiniana, C. vulgaris, C. kessleri, C. protothecoides and others. 226 The correct identity of UTEX 29 was found to be $C$. vulgaris rather than $C$. protothecoides in the 227 UTEX collection and UTEX 2714 was $C$. sorokiniana instead of $C$. vulgaris in the UTEX 
collection, which agrees with previous results by MUSCLE platform (Rosenberg et al., 2013).

229 Interestingly, UTEX 265 was identified as C. sorokiniana by MAFFT alignment and C. vulgaris 230 by MUSCLE, which may require further investigation for its definitive identification.

The physiology of Chlorella variabilis NC64A has been extensively studied and its 232 genome well-characterized; however, the maintenance of NC64A requires additional nutrients 233 such as peptone and its biomass production is lower than other Chlorella strains (Blanc et al., 234 2010). Therefore, it is critical to search for alternative strains in the Chlorella genus as platforms 235 for biomass production and species closely related to NC64A were selected: C. sorokiniana, C. 236 vulgaris, C. kessleri, C. protothecoides by rDNA-based phylogenetic analysis (Fig. 1). 237 Considering bioenergy applications, the levels of biomass and lipid production were compared 238 among the selected strains from C. sorokiniana, C. vulgaris, C. kessleri, C. protothecoides, C. 239 fusca var. vacuolata and C. zofingiensis.

244 vulgaris strains; UTEX 265, CS-01, UTEX 2805, 1230, 2714 and 246 for C. sorokiniana; UTEX 2452229 and 263 for C. kessleri; C. protothecoides UTEX B25; C. fusca var. vacuolate UTEX 252; 246 and C. zofingiensis UTEX 32 (Table 1). C. vulgaris UTEX 259, 29 and 395 and C. sorokiniana 247 UTEX 265, CS-01, 28051230 and 2714 exhibited high biomass production of greater than 296 $248 \mathrm{mg} \mathrm{L}^{-1} \mathrm{DW}$ at the maximal cell density in the different cultures, while the biomass of the strains 249 from C. kessleri, C. protothecoides, C. fusca var. vacuolate and C. zofingiensis was less than 262 
$250 \mathrm{mg} \mathrm{L}^{-1} \mathrm{DW}$ and was susceptible to rapid population decline during the growth cycle. The 251 maximal cell densities of C. vulgaris UTEX 29 and 395 were 467 and $400 \mathrm{mg} \mathrm{L}^{-1}$ DW under the 252 vigorous aeration $(0.38 \mathrm{vvm})$ containing $0.04 \% \mathrm{CO}_{2}$ from the atmosphere, respectively, and $C$. 253 sorokiniana UTEX 265, CS-01, UTEX 2805, 1230 and 2714 cell densities were 405, 491, 436,

254571 and $296 \mathrm{mg} \mathrm{L}^{-1} \mathrm{DW}$, respectively. The cell densities biomass production of $C$. vulgaris 255 UTEX 29, C. sorokiniana UTEX 265 and CS-01 reached maximal in 1 or $3 \mathrm{~L}$ bioreactors, while 256 C. vulgaris UTEX 259 and 395 and C. sorokiniana UTEX 2805, 1230 and 2714 reached 257 maximal in $80 \mathrm{~L}$ hanging-bags. The growth of $C$. sorokinian and C. vulgaris were lower or not 258 measurable in the aquarium tanks in comparison of bioreactors and hanging bags, which 259 indicates that the type and size of the culture vessel most likely affect biomass production due to 260 different light intensities and circulation patterns. Chinnasamy et al. also showed the higher 261 biomass productivities of the mixture culture (Chlamydomonas globasa, Chlorella minutissima 262 and Scenedesmus bijuga) at $21.1 \mathrm{~g} \mathrm{~m}^{-2} \mathrm{~d}^{-1}$ in the polyethylene hanging-bags rather than at $5.9 \mathrm{~g}$ $263 \mathrm{~m}^{-2} \mathrm{~d}^{-1}$ in the horizontal raceways by using the wastewater, which was due to the higher 264 photosynthetic efficiency (based on full solar spectrum) of $8.1 \%$ in the hanging-bags compared 265 to $1.0 \%$ in the raceways. This mixed culture study also demonstrated the requirement of more 266 air flow in raceways $\left(10 \mathrm{~L} \mathrm{~min}^{-1}\right)$ than in the hanging-bags $\left(0.4-0.8 \mathrm{~L} \mathrm{~min}^{-1}\right)$ (Chinnasamy et al., 267 2010). This indicates the optimal light intensity and aeration play important roles in algal 268 biomass productivity. Furthermore, the biomass production of C. kessleri, C. protothecoides, $C$. 269 fusca var. vacuolata and C. zofingiensis in BBM were lower than $263 \mathrm{mg} \mathrm{L}^{-1} \mathrm{DW}$ or 270 unmeasurable due to the requirement of higher nutrients in the media such as TAP, $\mathrm{B} 5, \mathrm{KNO}_{3}$ 271 rich- and Kuhl media (Liu et al., 2011; Shen et al., 2010; Shiratake et al., 2013). The large 
standard deviations of the biomass and dry weight were caused by the annual temperature

273 difference in the greenhouse although it is set at $25^{\circ} \mathrm{C}$.

274 The growth curves of $C$. sorokiniana CS-01, UTEX 1230, 2714, 265 and 2805, $C$. 275 vulgaris UTEX 395 and 259, C. kessleri UTEX 2229 and C. zofingiensis UTEX 32 were 276 compared in different type and size of culture; 1 or $3 \mathrm{~L}$ bioreactors, $80 \mathrm{~L}$ aquarium tanks and 80 277 L hanging-bags (Fig. 2). As the cell size of Chlorella is about $2 \mu \mathrm{m}$ in diameter and dry weight is 278 similar among the strains (e.g., the ratio of dry weight vs. cell density; UTEX $1230=4.6$; UTEX $2792714=4.9$; CS-01 $=4.8)$, the unit was expressed as cell density $\left(\right.$ cells $\left.\mathrm{ml}^{-1}\right)$. The growth curves 280 of C. sorokiniana UTEX 1230, 2714 and 2805, C. vulrgaris UTEX 395 and 259 showed the 281 range at cell density $74-131 \times 10^{6}$ cells ml${ }^{-1}$ in $80 \mathrm{~L}$ hanging-bags and $43-66 \times 10^{6} \mathrm{cells} \mathrm{ml}^{-1}$ in 1 282 or $3 \mathrm{~L}$ bioreactors under the vigorous aeration with $0.04 \%$ atmospheric $\mathrm{CO}_{2}$. In contrast, $C$. 283 sorokiniana CS-01 and UTEX 265 showed the cell density at $92-112 \times 10^{6}$ cells ml $^{-1}$ in the 1 or $2843 \mathrm{~L}$ bioreactors but $73 \times 10^{6}$ cells ml $^{-1}$ or were not measurable in $80 \mathrm{~L}$ hanging-bags since the 285 algae did not grow at the very early $\log$ phase (3-5 days after inoculation). C. sorokiniana CS-01 286 and UTEX 1230 in the $80 \mathrm{~L}$ aquarium tanks presented maximal cell densities of 73 and $87 \times 10^{6}$ 287 cells $\mathrm{ml}^{-1}$, respectively, however aquarium tanks did not produce as much as biomass as cultures 288 grown in bioreactors and hanging-bags. The growth differences in the different type and size 289 culture might be due to the difference of the light penetration and circulation of the Chlorella 290 strains in the culture. Other strains like C. kessleri UTEX 2229 and C. zofingiensis UTEX 32 291 either grew less than $60 \times 10^{6}$ cells ml $^{-1}$ or crashed easily during the growth cycle in all types and 292 sizes of cultures.

293 To address the question of whether C. sorokiniana or C. vulgaris produces more biomass 294 during autotrophic cultivation under vigorous aeration with $0.04 \% \mathrm{CO}_{2}$, C. sorokiniana UTEX 
295 1230, CS-01 and UTEX 2805 and C. vulgaris UTEX 395 and 259 were selected and the growth 296 curve data from Fig. 2 were combined to obtain the general growth curve patterns of $C$. 297 sorokiniana vs. C. vulgaris (Fig. 3 a). All cell densities of $C$. sorokiniana UTEX 1230, CS-01 298 and UTEX 2805 were in the range of 70-90 $\times 10^{6}$ cells ml $^{-1}$, while $C$. vulgaris UTEX 395 and 299259 were $27-35 \%$ lower at $45-66 \times 10^{6}$ cells $\mathrm{ml}^{-1}$, which demonstrates higher biomass 300 production of $C$. sorokiniana relative to $C$. vulgaris under the vigorous aeration with atmospheric $301 \mathrm{CO}_{2}$ levels at UNL. However, C. vulgaris UTEX 395 from NREL reached the cell density more 302 than $200 \times 10^{6}$ cells ml $^{-1}$ under $2 \% \mathrm{CO}_{2}$ condition in $1 \mathrm{~L}$ Roux bottle (Fig. $3 \mathrm{~b}$ ), which suggests 303 that supplemental $\mathrm{CO}_{2}$ might be required for the higher photoautotrophic biomass production in 304 C. vulgaris. The lipid contents of total lipid, FAME total lipid and TAG as the corresponding samples

308 of Fig. 2 were analyzed and quantified at the stationary phase in C. sorokiniana UTEX 1230, CS-01, UTEX 265 and 2714, C. vulgaris UTEX 395 and UTEX 259, C. kessleri UTEX 2229 and

310 C. zofingiensis UTEX 32 (Fig. 4). TAG is the neutral lipid which is chemically similar to most 311 conventional fuel and was obtained by removing the charged membrane lipids from FAME total 312 lipid on thin layer chromatography, while the other lipids such as total lipid from the extraction 313 or bio-crude from hydrothermal liquefaction (Chapman and Ohlrogge, 2012; Elliott, 2013) 314 contains a lot of charged moieties in the lipid chemical structures which may cause the 315 degradation of the oil. To access the quality and quantity of the accurate neutral lipid production 316 in algae, TAG analysis is critical. The contents of total lipid, FAME total lipid and TAG of the 
317 selected strains were measured at highest contents of $24,19,8 \% \mathrm{DW}$, respectively, in $C$. 318 sorokiniana UTEX 1230, 18, 13, 6 \% DW, respectively, in CS-01 and 17, 8, 7 \% DW in UTEX 319265 (Fig. 4 a), which indicates the high production of both membrane and storage lipid. The 320 contents of total lipid and FAME total lipid in C. sorokiniana UTEX 2714 were at the same 321 range of 22 and $14 \%$ DW, respectively, but TAG contents were less than $1 \%$ DW, which is 322 lower than UTEX 1230, 265 and CS-01. In C. vulgaris, the contents of total lipid, FAME total 323 lipid and FAME TAG were measured as 19, 16, 1 \% DW respectively in UTEX 395 and 16, 4, $324<1 \%$ DW, respectively, in UTEX 259 in which FAME TAG was hardly detected (Fig. 4 b). The 325 higher FAME total lipid contents but lower TAG contents may indicate more membrane lipid 326 synthesis than storage lipid accumulation. The difference between total lipid and FAME total 327 lipid in C. sorokiniana UTEX 265 and C. vulgaris UTEX 395 and 259 most likely include the 328 higher production of non-fatty acids such as chlorophylls, pigments, sterols, vitamins than fatty 329 acid. The lowest lipid contents were measured in C. kessleri UTEX 2229 and C. zofingiensis 330 UTEX 32. The contents of total lipid, FAME total lipid and FAME TAG were quantified at 16, $3317,<1 \%$ DW, respectively, in UTEX 2229 and 5, 3, <1\% DW, respectively, in UTEX 32 where 332 FAME TAG was also hardly detected (Fig. $4 \mathrm{c}$, d), which might indicate that lipids did not 333 manifest as both membrane and storage lipids due to the low growth rates. The results showed 334 the highest TAG accumulation as 6-8 \% DW in C. sorokiniana strains CS-01, UTEX 1230 and 335265.

337 3.4. Comparison of biomass and lipid production between C. sorokiniana UTEX 1230 vs. C. 338 vulgaris UTEX 395 and 295 under the ambient $\mathrm{CO}_{2}$ vigorous aeration and $3 \% \mathrm{CO}_{2}$ conditions 
C. vulgaris is one of the strongest candidates to produce high levels of biomass and lipids

340 in Chlorella strains according to the National Renewable Energy Laboratory (NREL) (Guarnieri

341 et al., 2011). Furthermore C. vulgaris UTEX 395 from NREL yielded higher cell density $200 \times$

$34210^{6}$ cells ml ${ }^{-1}$ under $2 \% \mathrm{CO}_{2}$ condition (Fig. 3 b) than $130 \times 10^{6}$ cells ml ${ }^{-1}$ of UTEX 1230 from

343 UNL under the vigorous aeration with ambient $\mathrm{CO}_{2}$ (Fig. 2, Table 1). The rDNA sequences of $C$.

344 sorokiniana UTEX 1230 and C. vulgaris UTEX 395 and 295 from NREL and University of

345 Nebraska-Lincoln (UNL) were confirmed identically by the MAFFT alignment and the biomass

346 and lipid contents were compared between C. sorokiniana UTEX 1230 vs. C. vulgaris UTEX

347395 and $259 ; 1)$ in $\mathrm{BBM}$ under the ambient $\mathrm{CO}_{2}$ vigorous aeration at flow rate $30 \mathrm{ml} \mathrm{min}^{-1}(0.38$

$348 \mathrm{vvm}$ ) and 2) in $\mathrm{BBM}$ with $3 \% \mathrm{CO}_{2}$ maintained in the $\mathrm{CO}_{2}$ saturated chamber (Fig. 5A). Since

349 the preliminary characterizations of $C$. sorokiniana and $C$. vulgaris growth varied between

350 NREL and UNL studies due to different growth conditions, such as $\mathrm{CO}_{2}$ concentration and

351 culture vessels (e.g., 1 L Roux bottles vs. large-scale photobioreactors), these strains were

352 compared under the same conditions to assess biomass and lipid production between $C$.

353 sorokiniana and C. vulgaris based on $\mathrm{CO}_{2}$ requirement. C. sorokiniana UTEX 1230 and CS-01

354 increased about 2 times from 123-144 to $483-652 \mathrm{mg} \mathrm{L}^{-1} \mathrm{DW}$ (cell density $110-150 \times 10^{6}$ cells

$355 \mathrm{ml}^{-1}$ ) with ambient $\mathrm{CO}_{2}$ vigorous aeration (Fig. $5 \mathrm{~A}, \mathrm{~b}$ ), while the biomass of $C$. vulgaris UTEX

356395 and 295 were less than $271 \mathrm{mg} \mathrm{L}^{-1}$ (cell density $60 \times 10^{6}$ cells ml${ }^{-1}$ ) under the ambient $\mathrm{CO}_{2}$

357 vigorous aeration, which agrees with the maximal cells densities reported in Table 1 and

358 indicates that the aeration is essential for the growth of $C$. sorokiniana UTEX 1230. The biomass

359 yields of $C$. sorokiniana UTEX 1230 and CS- 01 under the $3 \% \mathrm{CO}_{2}$ condition also reached the

360 same levels of $483-652 \mathrm{mg} \mathrm{L}^{-1}$ DW, however the biomass of C. vulgaris UTEX 395 and 295

361 produced $652-863 \mathrm{mg} \mathrm{L}^{-1} \mathrm{DW}$ (cell density $150-200 \times 10^{6} \mathrm{cells} \mathrm{ml}^{-1}$ ), which is approximately 3 
362 times higher than those of the ambient $\mathrm{CO}_{2}$ aeration condition (Fig. 5A, c) and imply that the

363 carbon concentrating mechanisms may be different between C. sorokiniana and C. vulgaris, 364 which the $\mathrm{pH}$ was constant at the same $\mathrm{pH}$ range (7.0-7.5) conditions during the growth cycle of 365 strains. The higher yield of biomass production under different $\mathrm{CO}_{2}$ concentration was reported 366 at the broad ranges of $\mathrm{CO}_{2}$ concentrations; $10.0 \mathrm{~g} \mathrm{~L}^{-1}$ dry weight in C. vulgaris under both $6.5 \%$ $367 \mathrm{CO}_{2}$ and $0.4 \mathrm{vvm}$ aeration (Anjos et al., 2013), 821-1303 $\mathrm{mg} \mathrm{L}^{-1}$ dry weight of C. vulgaris grown 368 in wastewater with addition of $5 \% \mathrm{CO}_{2}$ in air (Arbib et al., 2014) and $1.55 \mathrm{~g} \mathrm{~L}^{-1}$ in $C$. 369 pyrenoidosa under $10 \% \mathrm{CO}_{2}$ which demonstrated the best biomass production in comparison of $370 \quad 0.03-50 \%$ different $\mathrm{CO}_{2}$ application (Tang et al., 2011). The biomass of all strains without both 371 air and $\mathrm{CO}_{2}$ were under $261 \mathrm{mg} \mathrm{L}^{-1} \mathrm{DW}\left(60 \times 10^{6}\right.$ cells ml $\left.^{-1} \mathrm{DW}\right)$ (Fig. 5A, a), which is the same 372 range as UTEX 395 and 259 under the ambient $\mathrm{CO}_{2}$ vigorous aeration (Fig. 5A, b). These results 373 indicate that $C$. sorokiniana may be highly productive with minimal $\mathrm{CO}_{2}$ and vigorous aeration, 374 while $\mathrm{CO}_{2}$ supplementation is required for $C$. vulgaris to reach similar biomass yields. It is 375 important to determine the optimal $\mathrm{CO}_{2}$ and aeration level in various Chlorella strains.

The lipid contents of the corresponding samples were also quantified and compared 377 between $C$. sorokiniana UTEX 1230 and C. vulgaris UTEX 395 and 259 under ambient $\mathrm{CO}_{2}$ 378 aeration and $3 \% \mathrm{CO}_{2}$ conditions (Fig. 5B). The contents of total lipid, FAME total lipid, and 379 TAG of $C$. sorokiniana UTEX 1230 and CS-01 were measured at 23-26, 15-19, $8 \%$ DW, 380 respectively, under ambient $\mathrm{CO}_{2}$ vigorous aeration, while the contents of $C$. vulgaris UTEX 395 381 and 295 were at $18-19,7-18,<2 \%$ DW respectively which detection of FAME TAG was very 382 low under the ambient $\mathrm{CO}_{2}$ vigorous aeration (Fig. 5B, a). In contrast, total lipid, FAME total 383 lipid and TAG accumulation of C. vulgaris UTEX 395 under the $3 \% \mathrm{CO}_{2}$ condition increased to 38444,42 and $31 \%$ DW respectively which correspond to 2, 2, and 28 times higher accumulation 
under ambient $\mathrm{CO}_{2}$ vigorous aeration. The contents of total lipid, FAME total lipid, and TAG of C. vulgaris UTEX 259 were 39, 33, and $30 \%$ DW, respectively, which are roughly 2, 5, and 15 times higher accumulation respectively in comparison to ambient $\mathrm{CO}_{2}$ vigorous aeration. The 388 levels of FAME total lipid and TAG were same in C. vulgaris under the $3 \% \mathrm{CO}_{2}$ condition, 389 which may indicate the high storage lipid accumulation. Total lipid, FAME total lipid and TAG 390 of C. sorokiniana CS-01 increased to 33,25 , and $20 \%$ DW, respectively, which are $1.4,1.6$ and 3912.5 times higher than under the ambient $\mathrm{CO}_{2}$ vigorous aeration, however all lipid contents of $C$. sorokiniana UTEX 1230 under the $3 \% \mathrm{CO}_{2}$ condition were at the same ranges as those under 393 the ambient $\mathrm{CO}_{2}$ vigorous aeration. A dramatic difference was observed between $C$. sorokiniana 394 and $C$. vulgaris under the ambient $\mathrm{CO}_{2}$ vigorous aeration and $3 \% \mathrm{CO}_{2}$ condition. The results 395 indicate that the $\mathrm{CO}_{2}$ treatment includes both strains of $C$. vulgaris and C. sorokiniana CS-01 to 396 produce higher biomass and lipid contents, especially high levels of TAG accumulation, while it 397 does not affect $C$. sorokiniana UTEX 1230. In a previous study performed with $C$. vulgaris 398 UTEX 395, the FAME lipid content was measured as more than $10 \%$ in nitrogen replete 399 conditions and $60 \%$ in nitrogen deplete conditions with $2 \% \mathrm{CO}_{2}$ supplement (Guarnieri et al., 400 2011). TAG contents of C. sorokiniana UTEX 1230 under heterotrophic condition with glucose 401 and without light accumulated to $24-39 \%$ DW also at the same level as the FAME total lipid 402 contents (Rosenberg et al., 2013). This indicates that $\mathrm{CO}_{2}$ is required for both biomass and lipid 403 accumulation for $C$. vulgaris, while C. sorokiniana UTEX 1230 can achieve comparable biomass 404 densities with the continuous air, but its lipid and biomass production can be enhanced by other 405 carbon sources, such as glucose. This might suggest that $C$. vulgaris and C. sorokiniana have 406 different $\mathrm{HCO}_{3}{ }^{-}$transporters (Duanmu et al., 2009). 
The main fatty acid compositions of all these strains under both ambient $\mathrm{CO}_{2}$ vigorous

408 aeration and $3 \% \mathrm{CO}_{2}$ conditions in FAME total lipid and TAG were detected as 16:0, 18:1, 18:2

409 and 18:3 (carbon : double bond number), which are the main FAME in Chlorella (Fig. 5B, c-f)

410 (Hu et al., 2008). The FAME total lipid and TAG levels of 16:0, 18:1, 18:2 and 18:3 in $C$.

411 sorokiniana UTEX 1230 and CS-01 remained within the same ranges both under the ambient

412 and $3 \% \mathrm{CO}_{2}$ conditions, however the level of 18:1 of C. vulgaris UTEX 395 and 259 increased

413 from 1.6-2.5 \% to 14-19\% DW in FAME total lipid (Fig. 5B, c, d) and 0.4-0.8 \% to 13-14\%

414 DW in FAME TAG (Fig. 5B, e, f). The main FAMEs, 16:0, 18:2 and 18:3 in FAME total lipid

415 were the same range at 2-8, 0.8-4.5, and 1.8-5.8 \% DW respectively in C. vulgaris UTEX 395

416 and 259 both under the ambient $\mathrm{CO}_{2}$ vigorous aeration and $3 \% \mathrm{CO}_{2}$ conditions (Fig. 5B, c, d),

417 while 16:0, 18:2 and 18: 3 in FAME TAG increased from 0.007-0.011, 0.02-0.3 and 0.12-0.37\%

418 under ambient $\mathrm{CO}_{2}$ vigorous aeration to 5.6-5.8, 2.7-2.8 and 3.6-5.0 \% DW with $3 \% \mathrm{CO}_{2}$

419 condition, respectively (Fig. 5B, e, f), which also demonstrated higher TAG accumulation with

420 supplemental $\mathrm{CO}_{2}$. The lipid composition (18:1) of FAME total lipid and (16:0, 18:1, 18:2 and

421 18:3) in TAG increased in C. vulgaris UTEX 395 and 259 under the $3 \% \mathrm{CO}_{2}$ condition. In

422 particular, 18:1 was 16-35 times higher under the $3 \% \mathrm{CO}_{2}$ condition compared to ambient $\mathrm{CO}_{2}$

423 vigorous aeration. In contrast, the lipid composition (18:2) of C. sorokiniana UTEX 1230 under

424 heterotrophic condition increased dominantly in the lipid composition (Rosenberg et al., 2013),

425 which may indicate the involvement of desaturase in plastid or endoplasmic reticulum observed

426 in plants (Chapman and Ohlrogge, 2012; Wallis and Browse, 2002).

427

428 4. Conclusion 
After selecting the Chlorella species by rDNA based-phylogenetic analysis and screening

430 their biomass and lipid production, $C$. sorokiniana and C. vulgaris demonstrated the highest

431 biomass and lipid production among other species. Comparison of different levels of $\mathrm{CO}_{2}$ during

432 the growth of $C$. sorokiniana and $C$. vulgaris showed higher biomass and lipid production in $C$.

433 sorokiniana under conditions of ambient $\mathrm{CO}_{2}$ vigorous aeration, while $C$. vulgaris prospers more

434 with $3 \% \mathrm{CO}_{2}$. For biofuels applications, the Chlorella strains examined in this study represent

435 that carbon can be uniquely paired based on the abundant natural resources sources (i.e., 436 industrial $\mathrm{CO}_{2}$ or organic wastes).

\section{Acknowledgements}

Authors express their gratitude to Dr. James Van Etten at University of Nebraska-Lincoln

440 for providing us C. variabilis NC64A and Dr. Minxi Wan at Johns Hopkins University for $C$.

441 sorokiniana CS-01. Authors also acknowledge Drs. Concetta DiRusso and Paul Black for access

442 of GC/MS. This work was supported by a Department of Energy (DOE) algae biofuel

443 commercialization grant (CAB-Comm) and a National Science Foundation (NSF) program,

444 Experimental Program to Stimulate Competitive Research (EPSCoR) grant at University of 445 Nebraska-Lincoln. 
448 Fig. 1 Proposed phylogenetic tree of rDNA gene sequences from Chlorella species. Selected 449 sequences from the NCBI database were included. Grey arrows; the strains used in this study. 450 Black arrow; the characterized genome of $C$. variabilis NC64A (Blanc et al., 2010).

451 Fig. 2 Growth curves of Chlorella species in different types and sizes of culture. A, 80 L 452 hanging-bag; B, 80 L aquarium tank; C, 1 or 3 L bioreactors. Black lines and symbols, Chlorella 453 sorokiniana CS-01, UTEX 1230, UTEX 2714, UTEX 265 and UTEX 2805; Grey lines and 454 symbols, C. vulgaris UTEX 395 and UTEX 259; White grey lines and symbols, C. kessleri 455 UTEX 2229 and C. zofingiensis UTEX 32. Error bar: standard deviation of three biological 456 replicates.

457 Fig. 3 Comparison of the growth patterns between C. sorokiniana and C. vulgaris under 458 vigorous aeration with ambient atmospheric $\mathrm{CO}_{2}$ (UNL). Each growth curve was combined from 459 the results of hanging-bags and bioreactors (a). Growth curve of C. vulgaris UTEX 395 grown in $4601 \mathrm{~L}$ Roux Bottle under $2 \% \mathrm{CO}_{2}$ condition at NREL (b). The graph was converted from OD (750 $461 \mathrm{~nm})$ to cell count based on the equation $(\mathrm{y}=00398 \mathrm{x}-0.0245)$ of the relationship between cell 462 count and OD (750 nm) in Chlorella.

463 Fig. 4 Lipid contents of C. sorokiniana, C. vulgaris, C. kessleri and C. zofingiensis. a, Chlorella 464 sorokiniana UTEX 1230, CS-01, UTEX 2714 and UTEX 265; b, C. vulgaris UTEX 395 and 465 UTEX 259; c, C. kessleri UTEX 2229 and d, C. zofingiensis UTEX 32. Black bar; total lipid, 466 grey bar; FAME total lipid; white grey bar; FAME TAG. Error bars: standard deviation of 467 three technical replicates.

468 Fig. 5 Comparison of growth curves (A) and lipid analyses (B) of C. sorokiniana UTEX 1230 469 and C. vulgaris UTEX 395 and 259 under ambient and $3 \% \mathrm{CO}_{2}$ conditions. A. Growth curves of 
470 UTEX 1230 and CS-01 (black), UTEX 395 and UTEX 259 (grey). a; no air and CO $_{2}$ application,

471 b; ambient $\mathrm{CO}_{2}$ vigorous aeration, c; $3 \% \mathrm{CO}_{2}$ application. B. Lipid contents under ambient (a)

472 and $3 \% \mathrm{CO}_{2}$ (b) conditions. Black column; Total lipid, grey column; FAME total lipid and white

473 grey column; FAME TAG. Fatty acid analysis of FAME total lipid under ambient (c) and $3 \%$

$474 \mathrm{CO}_{2}(\mathrm{~d})$ conditions. Fatty acid analysis of FAME TAG under the ambient (e) and $3 \% \mathrm{CO}_{2}$ (f).

475 Black column, UTEX 1230 and dark grey, CS-01, Chlorella sorokiniana; light grey column,

476 UTEX 395 and white grey, UTEX 259, Chlorella vulgaris. Error bar: standard deviation of six

477 biological replicates for panel A graph b and c and three biological replicates for panel A graph

478 a.

479

480

481

482

483

484

485

486

487

488 


\section{References}

1. Ahmad, I., Fatma, Z., Yazdani, S.S., Kumar, S., 2013. DNA barcode and lipid analysis of new marine algae potential for biofuel. Algae Research, 2, 10-15.

2. Anjos, M., Fernandes, B.D., Vicente, A.A., Teixeira, J.A., Dragone, G., 2013. Optimization of $\mathrm{CO}$ (2) bio-mitigation by Chlorella vulgaris. Bioresour Technol, 139, 149-54.

3. Arbib, Z., Ruiz, J., Alvarez-Diaz, P., Garrido-Perez, C., Perales, J.A., 2014. Capability of different microalgae species for phytoremediation processes: wastewater tertiary treatment, CO2 bio-fixation and low cost biofuels production. Water Res, 49, 465-74.

4. Blanc, G., Duncan, G., Agarkova, I., Borodovsky, M., Gurnon, J., Kuo, A., Lindquist, E., Lucas, S., Pangilinan, J., Polle, J., Salamov, A., Terry, A., Yamada, T., Dunigan, D.D., Grigoriev, I.V., Claverie, J.M., Van Etten, J.L., 2010. The Chlorella variabilis NC64A genome reveals adaptation to photosymbiosis, coevolution with viruses, and cryptic sex. Plant Cell, 22, 2943-55.

5. Bligh, E.G., Dyer, E.J., 1959. A rapid method of total lipid extraction and purification. Can J Biochem Physiol, 37, 911-917.

6. Bold, H.C., 1949. The morphology of Chlamydomonas chlamydogama sp. nov. Bull. Torrey Bot. Club, 76, 101-108.

7. Bumbak, F., Cook, S., Zachleder, V., Hauser, S., Kovar, K., 2011. Best practices in heterotrophic high-cell-density microalgal processes: achievements, potential and possible limitations. Appl Microbiol Biotechnol, 91, 31-46.

8. Cha, T.S., Chen, J.W., Goh, E.G., Aziz, A., Loh, S.H., 2011. Differential regulation of fatty acid biosynthesis in two Chlorella species in response to nitrate treatments and the potential of binary blending microalgae oils for biodiesel application. Bioresour Technol, 102, 10633-40.

9. Chapman, K.D., Ohlrogge, J.B., 2012. Compartmentation of triacylglycerol accumulation in plants. J Biol Chem, 287, 2288-94.

10. Chinnasamy, S., Bhatnagar, A., Claxton, R., Das, K.C., 2010. Biomass and bioenergy production potential of microalgae consortium in open and closed bioreactors using untreated carpet industry effluent as growth medium. Bioresour Technol, 101, 6751-60.

11. Dismukes, G.C., Carrieri, D., Bennette, N., Ananyev, G.M., Posewitz, M.C., 2008. Aquatic phototrophs: efficient alternatives to land-based crops for biofuels. Curr Opin Biotechnol, 19, 235-40.

12. Duanmu, D., Miller, A.R., Horken, K.M., Weeks, D.P., Spalding, M.H., 2009. Knockdown of limiting-CO2-induced gene $\mathrm{HLA} 3$ decreases $\mathrm{HCO} 3$ - transport and photosynthetic $\mathrm{Ci}$ affinity in Chlamydomonas reinhardtii. Proc Natl Acad Sci U S A, 106, 5990-5.

13. Durrett, T.P., Benning, C., Ohlrogge, J., 2008. Plant triacylglycerols as feedstocks for the production of biofuels. Plant J, 54, 593-607.

14. Elliott, D.C., Hart, T.R., Schmidt, A.J., Neuenschwander, G.G., Rotness, L.J., Olarte, M.V., Zacher, A.H., Albrecht, K.O., Hallen, R.T., Holladay, J.E., 2013. Process development for hydrothermal liquefaction of algae feed stocks in a continuous-flow reactor. Algal Research, 2, 445-454.

15. Greenwell, H.C., Laurens, L.M., Shields, R.J., Lovitt, R.W., Flynn, K.J., 2009. Placing microalgae on the biofuels priority list: a review of the technological challenges. J R Soc Interface, 7, 703-26.

16. Guarnieri, M.T., Nag, A., Smolinski, S.L., Seibert, M., Pienkos, P.T., 2011. Examination of triacylglycerol biosynthetic pathway via de novo transcriptomic and proteomic analyses in an unsequenced microalgae. PlosONE, 6, e25851.

17. Hu, Q., Sommerfeld, M., Jarvis, E., Ghirardi, M., Posewitz, M., Seibert, M., Darzins, A., 2008. Microalgal triacylglycerols as feedstocks for biofuel production: perspectives and advances. Plant J, 54, 621-39. 
540

18. Katoh, K., Standley, DM.,, 2014. MAFFT : interative refinement and additional methods. Methods Mol Biol., 1079, 131-46.

19. Kobayashi, N., Noel, E.A., Barnes, A., Rosenberg, J., DiRusso, C., Black, P., Oyler, G.A., 2013. Rapid detection and quantification of triacylglycerol by HPLC-ELSD in Chlamydomonas reinhardtii and Chlorella strains. Lipids, 48, 1035-49.

20. Kobayashi, N., Noel, E.A., Barnes, A., Watson, A., Rosenberg, J.N., Erickson, G., Oyler, G.A., 2013. Characterization of three Chlorella sorokiniana strains in anaerobic digested effluent from cattle manure. Bioresour Technol, 150, 377-86.

21. Liang, Y., Sarkany, N., Cui, Y., 2009. Biomass and lipid productivities of Chlorella vulgaris under autotrophic, heterotrophic and mixotrophic growth conditions. Biotechnol Lett, 31, 1043-9.

22. Liu, J., Huang, J., Sun, Z., Zhong, Y., Jiang, Y., Chen, F., 2011. Differential lipid and fatty acid profiles of photoautotrophic and heterotrophic Chlorella zofingiensis: assessment of algal oils for biodiesel production. Bioresour Technol, 102, 106-10.

23. Rodolfi, L., Chini Zittelli, G., Bassi, N., Padovani, G., Biondi, N., Bonini, G., Tredici, M.R., 2009. Microalgae for oil: strain selection, induction of lipid synthesis and outdoor mass cultivation in a low-cost photobioreactor. Biotechnol Bioeng, 102, 100-12.

24. Rosenberg, J.N., Kobayashi, N., Barnes, A., Noel, E.A., Betenbaugh, M.J., Oyler, G.A., 2013. Comparative analyses of three microalgae (Chlorella) in response to light and sugar reveal differential lipid accumulation patterns in C. sorokiniana UTEX 1230. PlosONE.

25. Schenk, P.M., Thomas-Hall, S.R., Stephens, E., Marx, U.C., Mussgnug, J.H., Posten, C., Kruse, O., Hankamer B., 2008. Second Generation Biofuel: High-Efficiency Microalgae for Biodiesel Production. Bioenerg. Res, 1, 20-43.

26. Shen, Y., Yuan, W., Pei, Z., Mao, E., 2010. Heterotrophic culture of Chlorella protothecoides in various nitrogen sources for lipid production. Appl Biochem Biotechnol, 160, 1674-84.

27. Shiratake, T., Sato, A., Minoda, A., Tsuzuki, M., Sato, N., 2013. Air-Drying of Cells, the Novel Conditions for Stimulated Synthesis of Triacylglycerol in a Green Alga, Chlorella kessleri. PlosONE, 8, e79630.

28. Singh, M., Reynolds, D.L., Das, K.C., 2011. Microalgal system for treatment of effluent from poultry litter anaerobic digestion. Bioresour Technol, 102, 10841-8.

29. Tang, D., Han, W., Li, P., Miao, X., Zhong, J., 2011. CO2 biofixation and fatty acid composition of Scenedesmus obliquus and Chlorella pyrenoidosa in response to different CO2 levels. Bioresour Technol, 102, 3071-6.

30. Tang, H., Chen, M., Ng, K.Y., Salley, S.O., 2012. Continuous microalgae cultivation in a photobioreactor. Biotechnol Bioeng, 109, 2468-74.

31. Wallis, J.G., Browse, J., 2002. Mutants of Arabidopsis reveal many roles for membrane lipids. Prog Lipid Res, 41, 254-78.

32. Wan, M., Rosenberg, J.N., Faruq, J., Betenbaugh, M.J., Xia, J., 2011. An improved colony PCR procedure for genetic screening of Chlorella and related microalgae. Biotechnol Lett, 33, 1615-9.

33. Zheng, Y., Chi, Z., Lucker, B., Chen, S., 2012. Two-stage heterotrophic and phototrophic culture strategy for algal biomass and lipid production. Bioresour Technol, 103, 484-8. 
Table 1 Biomass and stationary days of Chlorella species in different container size of cultivation.

\begin{tabular}{|c|c|c|c|c|c|c|c|c|c|}
\hline \multirow{2}{*}{$\begin{array}{l}\text { Chlorella } \\
\text { strains }\end{array}$} & \multicolumn{3}{|c|}{ Bioreactors } & \multicolumn{3}{|c|}{ Aquarium tanks } & \multicolumn{3}{|c|}{ Hanging-bags } \\
\hline & $\begin{array}{c}\text { Stationary } \\
\text { phase } \\
\text { (days) }\end{array}$ & $\begin{array}{l}\text { Cell density } \\
\left(\mathrm{x} 10^{6} \text { cell } \mathrm{ml}^{-1}\right)\end{array}$ & $\begin{array}{l}\text { Dry weight } \\
\left(\mathrm{mg} \mathrm{L}^{-1}\right)\end{array}$ & $\begin{array}{c}\text { Stationary } \\
\text { phase } \\
\text { (days) }\end{array}$ & $\begin{array}{l}\text { Cell density } \\
\left(\mathrm{x} 10^{6} \text { cell } \mathrm{ml}^{-1}\right)\end{array}$ & $\begin{array}{l}\text { Dry weight } \\
\left(\mathrm{mg} \mathrm{L}^{-1}\right)\end{array}$ & $\begin{array}{c}\text { Stationary } \\
\text { phase } \\
\text { (days) }\end{array}$ & $\begin{array}{l}\text { Cell density } \\
\left(\mathrm{x} 10^{6} \text { cell } \mathrm{ml}^{-1}\right)\end{array}$ & $\begin{array}{l}\text { Dry weight } \\
\left(\mathrm{mg} \mathrm{L}^{-1}\right)\end{array}$ \\
\hline \multicolumn{10}{|c|}{ Chlorella vulgaris } \\
\hline UTEX 259 & 14 & $44.93 \pm 8.11^{\mathrm{a}}$ & $207.46 \pm 34.29^{\mathrm{a}}$ & - & - & - & 23 & 85.6 & 379.48 \\
\hline UTEX 29 & 13 & $106.20 \pm 2.40^{\mathrm{a}}$ & $466.62 \pm 10.15^{\mathrm{a}}$ & 15 & 62.8 & 283.03 & - & - & - \\
\hline UTEX 395 & 9 & $60.20 \pm 30.21^{\mathrm{a}}$ & $272.04 \pm 127.80^{\mathrm{a}}$ & 15 & 52.6 & 239.89 & 20 & $90.60 \pm 33.95^{\mathrm{a}}$ & $400.63 \pm 143.60^{\mathrm{a}}$ \\
\hline \multicolumn{10}{|c|}{ C. sorokiniana } \\
\hline UTEX 265 & 14 & $91.80 \pm 29.42^{\mathrm{a}}$ & $405.70 \pm 124.43^{\mathrm{a}}$ & 7 & 34.4 & 162.90 & - & - & - \\
\hline CS-01 & 9 & $112.00 \pm 21.38^{\mathrm{a}}$ & $491.15 \pm 66.91^{\mathrm{a}}$ & 17 & $87.30 \pm 6.47^{\mathrm{a}}$ & $\begin{array}{c}386.67 \pm 27.1 \\
4^{\mathrm{a}}\end{array}$ & 15 & $72.67 \pm 26.35^{\mathrm{a}}$ & $324.77 \pm 111.46^{\mathrm{a}}$ \\
\hline UTEX 2805 & 13 & 58.9 & 266.54 & - & - & - & 15 & 99.0 & 436.16 \\
\hline UTEX 1230 & 8 & $42.90 \pm 9.38^{\mathrm{a}}$ & $198.85 \pm 39.67^{\mathrm{a}}$ & 14 & $73.15 \pm 2.57^{\mathrm{a}}$ & $\begin{array}{c}326.80 \pm 10.8 \\
6^{\mathrm{a}}\end{array}$ & 22 & $130.93 \pm 15.40^{\mathrm{a}}$ & $571.24 \pm 65.29^{a}$ \\
\hline UTEX 2714 & 13 & 65.8 & 295.72 & - & - & - & 20 & $74.15 \pm 12.94^{\mathrm{a}}$ & $296.26 \pm 54.74^{\mathrm{a}}$ \\
\hline UTEX 246 & 14 & 56.0 & 254.27 & - & - & - & - & - & - \\
\hline \multicolumn{10}{|l|}{ C. kessleri } \\
\hline UTEX 2229 & 15 & $31.58 \pm 12.22^{\mathrm{a}}$ & $150.99 \pm 51.69^{\mathrm{a}}$ & 7 & 29.5 & 142.18 & 16 & 23.0 & 114.68 \\
\hline UTEX 263 & - & - & - & 14 & 38.5 & 180.25 & - & - & - \\
\hline \multicolumn{10}{|c|}{ C. protothecoide } \\
\hline UTEX B25 & - & - & - & 14 & 58.0 & 262.73 & - & - & - \\
\hline \multicolumn{10}{|c|}{ C. fusca var. vaculata } \\
\hline UTEX 252 & - & - & - & 16 & 25.3 & 124.41 & - & - & - \\
\hline \multicolumn{10}{|c|}{ C. zofingiensis } \\
\hline UTEX 32 & 14 & 42.8 & 198.43 & 7 & 54.1 & 246.23 & - & - & - \\
\hline
\end{tabular}

${ }^{\mathrm{a}}$ Standard deviation from three biological replicates, -Not measured. 
Figure 1

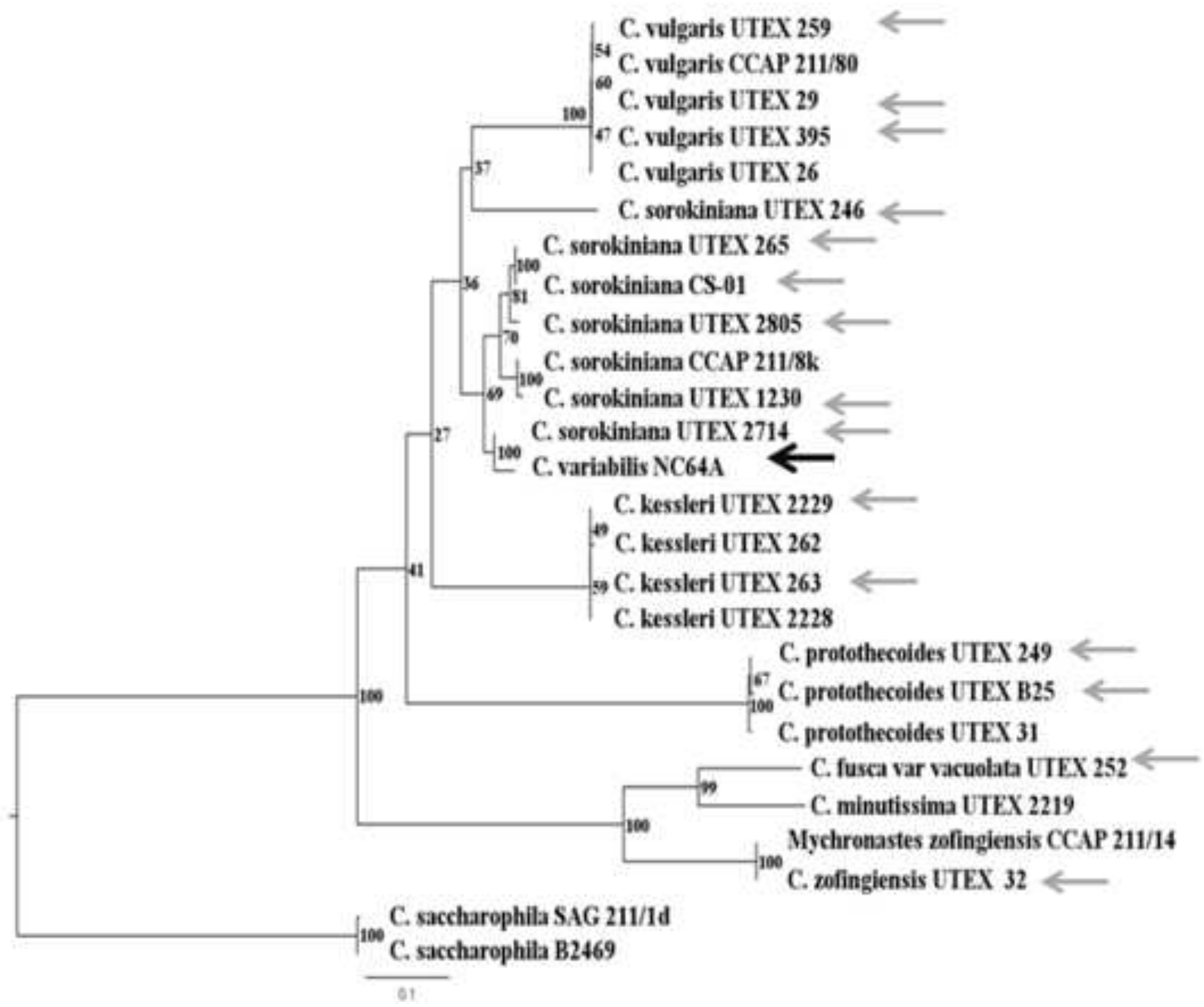


Figure 2

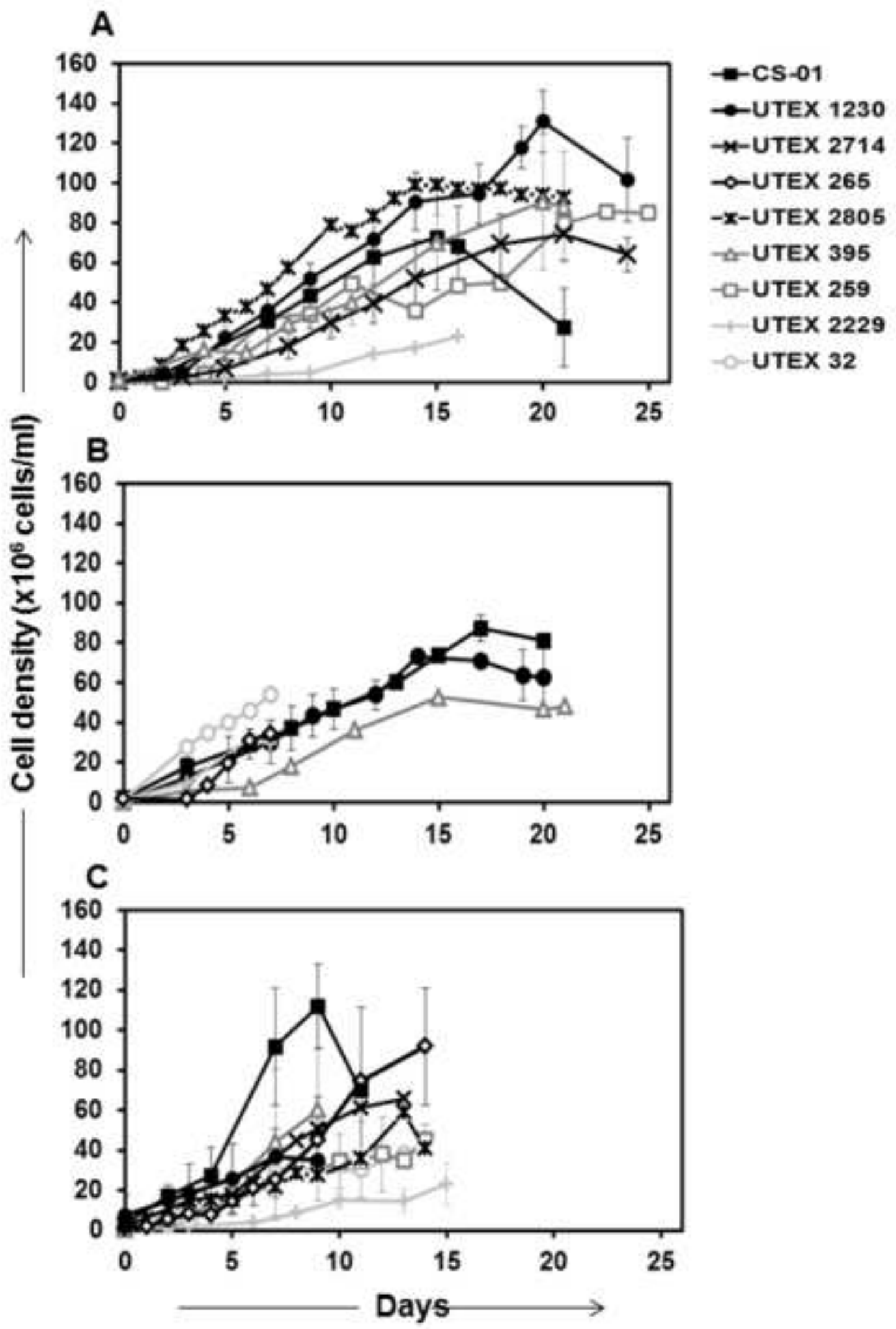


Figure 3

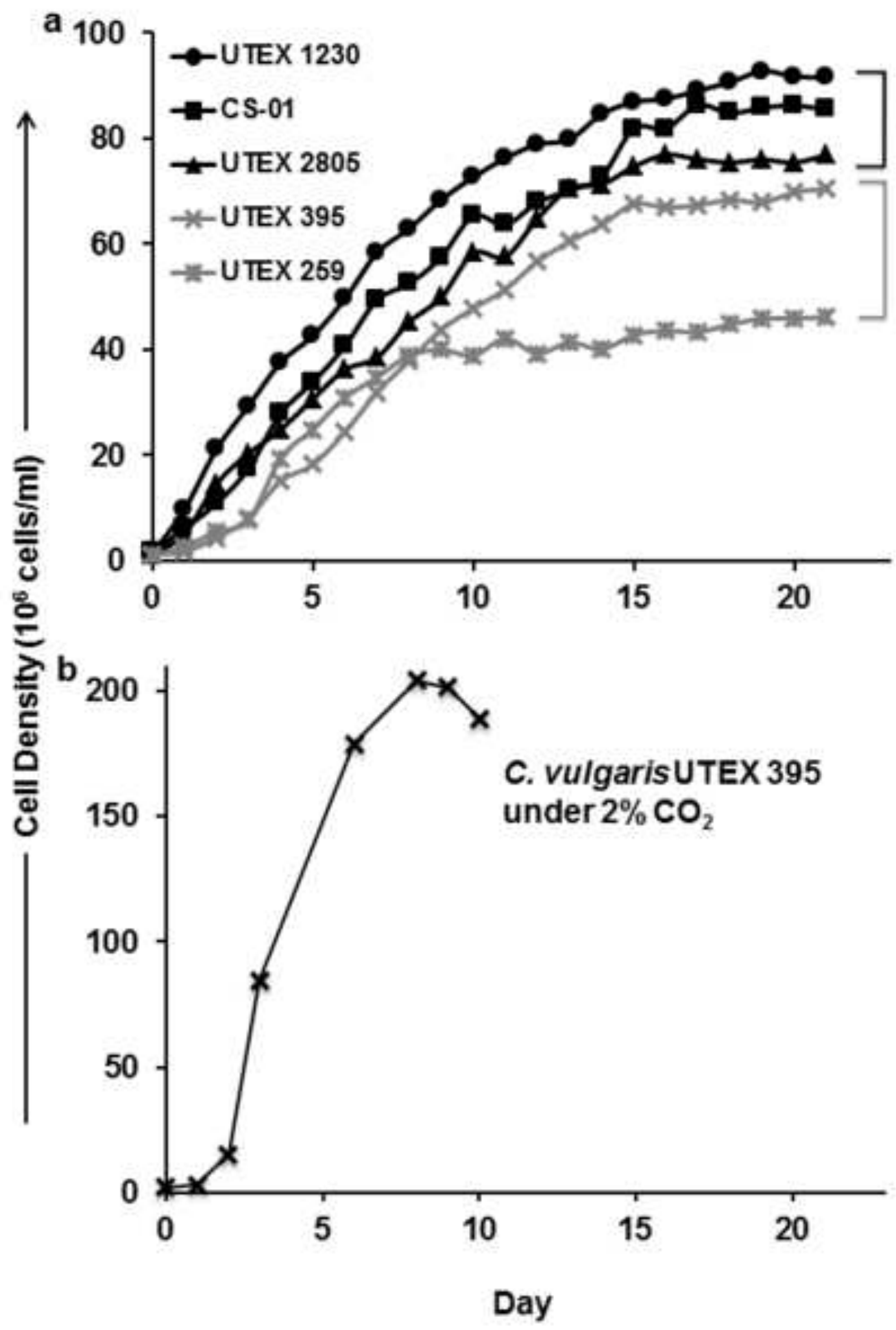

C. sorokiniana

C. vulgaris 
Figure 4
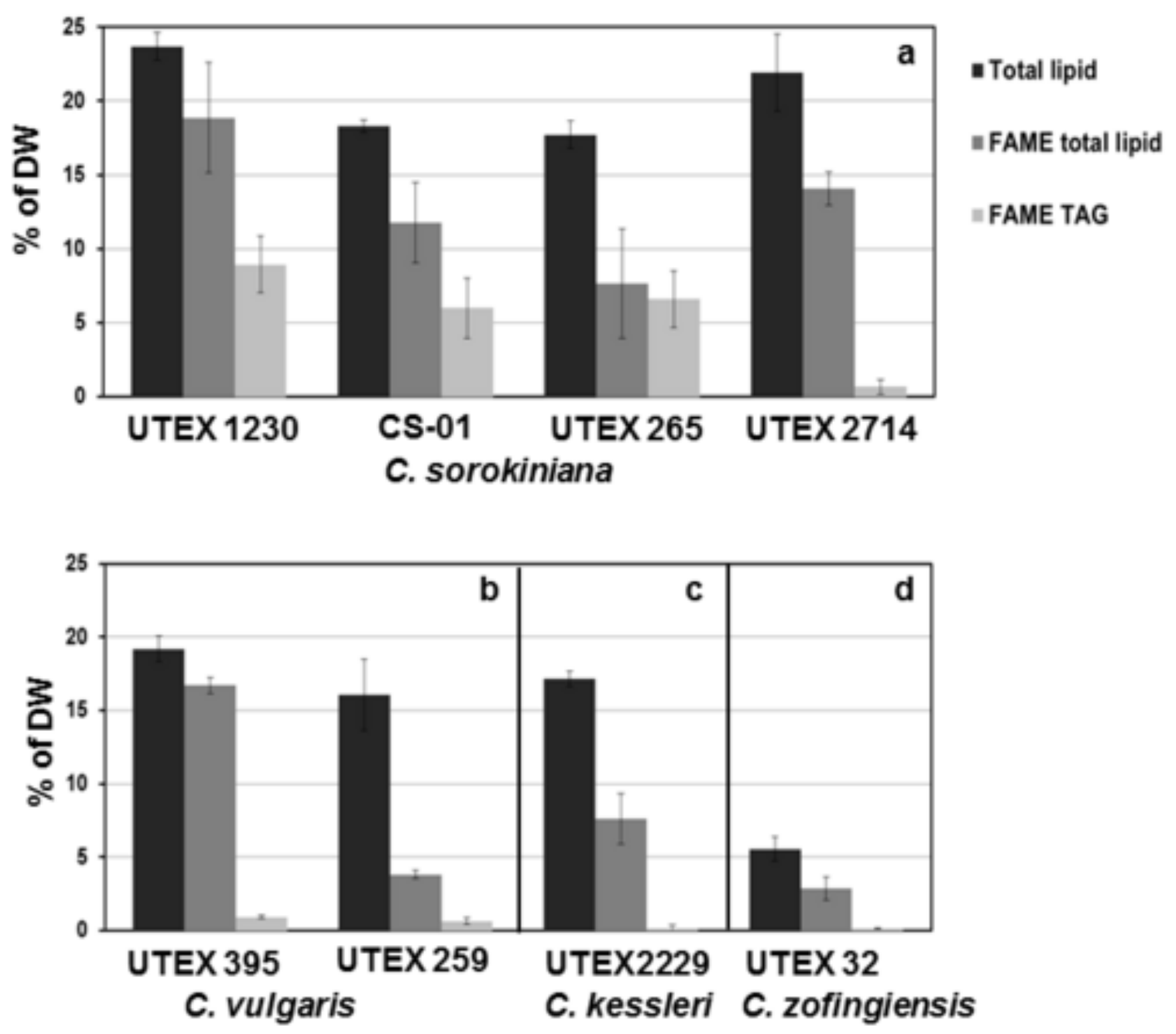

Figure 4 
Figure 5

\section{A}
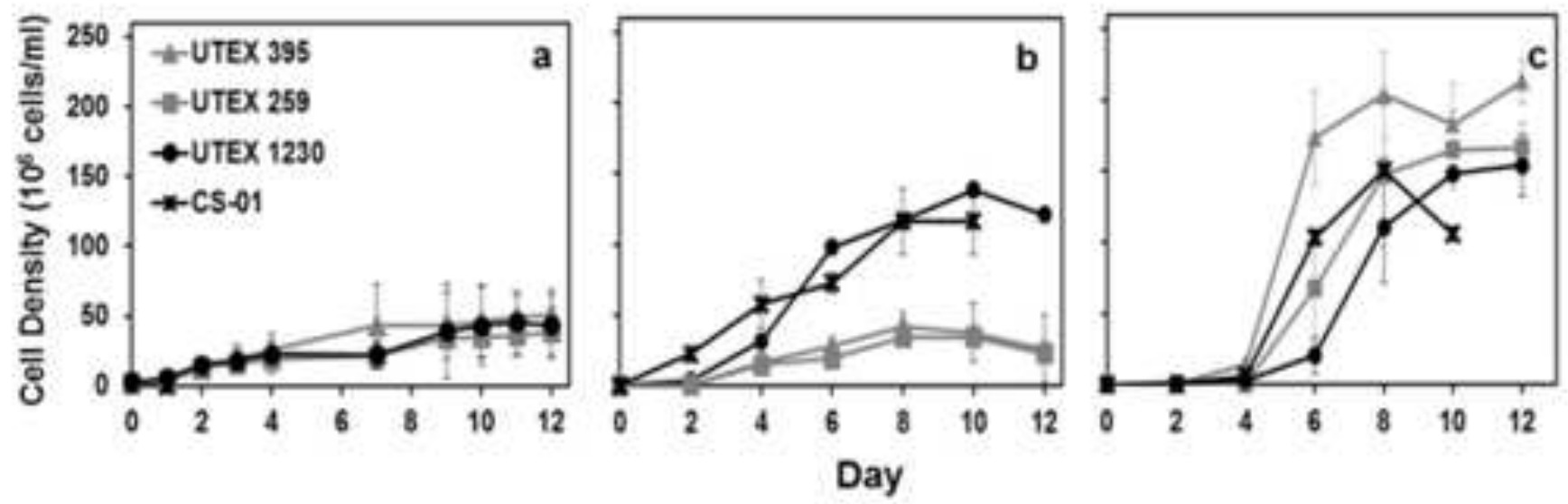

Day

B
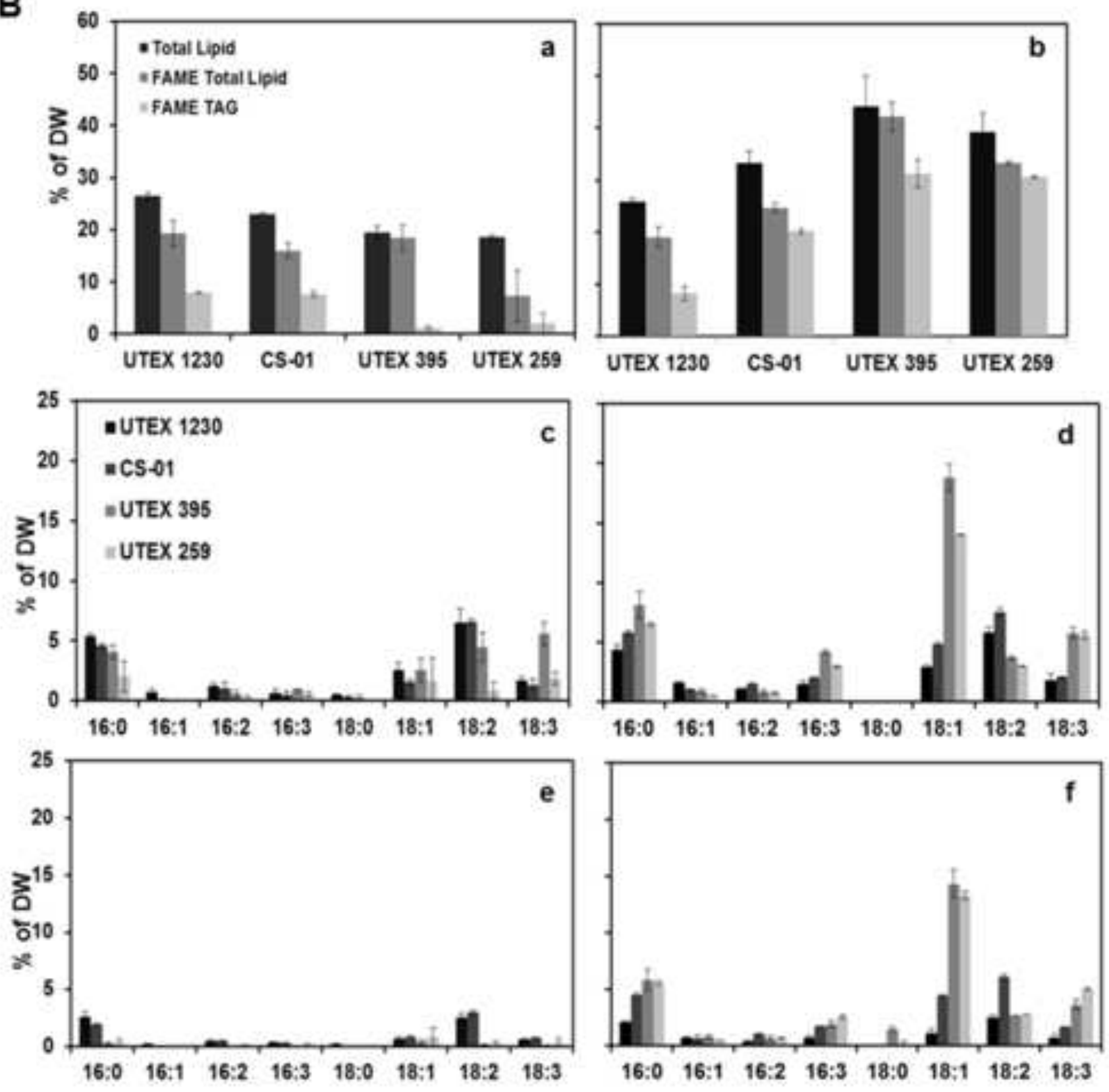